\title{
FUSARIUM LEVELS IN GRAIN HARVESTED FROM NEW ZEALAND WHEAT AND BARLEY CROPS IN 2000
}

\author{
M.G. CROMEY, R.A. PARKES and P.M. FRASER
}

\author{
New Zealand Institute for Crop \& Food Research Limited, Private Bag 4704, \\ Christchurch \\ Corresponding author: cromeym@crop.cri.nz
}

\begin{abstract}
Samples of grain from 40 New Zealand wheat and barley crops harvested in 2000 were assayed for Fusarium infection. Grain from all crops was infected, and Fusarium incidence ranged from 3 to $52 \%$ of grains infected, with a mean of $14 \%$. Incidence of Fusarium was higher in spring wheat than in autumn wheat or spring barley. The highest level of infection (52\% grains infected) was found in Otane wheat (highly susceptible to Fusarium head blight) sown into a paddock after maize, although there were no general effects of cropping history on grain infection. Levels were lower when residues of the previous crop were burned rather than baled or incorporated. Infection levels varied between cultivars, corresponding to the variability in susceptibility to Fusarium head blight. Keywords: Head scab, Fusarium head blight, Fusarium, wheat, barley.
\end{abstract}

\section{INTRODUCTION}

In recent years, Fusarium diseases (crown rot, root rots and Fusarium head blight) have become of increasing concern in New Zealand cereal crops. These diseases are caused by complexes of Fusarium species, and the species mixture varies between regions (Sayer \& Lauren 1991).

Fusarium head blight (FHB), also known as head scab, is most easily recognised on immature heads of cereal plants where one or more spikelets in each head appear prematurely bleached. Sometimes large areas of heads may be affected and, where infection is severe, pink or orange spore masses can be seen on diseased spikelets. FHB can reduce yield by $30-70 \%$ where conditions favour the disease, but more importantly Fusarium-infected grain from affected crops may be less palatable to stock than healthy grain and may contain mycotoxins (Bai \& Shaner 1994).

Cereal-infecting Fusarium spp. survive in host residues in or on the soil, and usually remain only as long as residues of susceptible hosts remain. Residue management, cultivation method, cropping sequence and herbicide usage can affect the quantity and duration of crop and weed residues. The cereal Fusarium spp. have a wide host range amongst cereals and grasses, as well as some broadleaf weeds.

In this study we examined the associations of crop type, region and crop management with Fusarium infection in samples of grain harvested from New Zealand wheat and barley crops in 2000, as a preliminary step in determining the factors influencing infection.

\section{MATERIALS AND METHODS}

Forty crops were selected for this survey from the major cereal-growing areas of New Zealand. Eight crops were in the North Island (Manawatu and Rangatikei), seven in North Canterbury, 13 in Mid Canterbury, eight in South Canterbury and four were in Southland. Thirteen crops were autumn wheat, 11 were spring wheat and 16 were spring barley.

Ear samples (at least 50 per crop) were collected from crops along a diagonal when ripe, manually threshed and grain assessed for level of Fusarium infection. In a few cases, samples were from the harvested crop. One hundred grains from each crop were surface sterilised with $1 \%$ sodium hypochlorite for $10 \mathrm{~min}$, washed twice with sterile distilled 
water, and plated (10 grains per plate) onto Difco potato dextrose agar (PDA) amended with antibiotics $(120 \mathrm{mg} / \mathrm{ml}$ streptomycin, $50 \mathrm{mg} / \mathrm{ml}$ aureomycin and $50 \mathrm{mg} / \mathrm{ml}$ chloramphenicol). Numbers of Fusarium colonies were assessed between 5 and 8 days, and colonies were subcultured onto PDA and carnation leaf agar (CLA) for identification to species level, using the methods of Burgess et al. (1994). Carnation leaf agar was prepared by placing sterile 5-8 $\mathrm{mm}$ carnation leaf pieces (approximately 1 piece per $3 \mathrm{ml}$ agar) on $2 \%$ Water Agar plates when almost set.

Growers were sent a questionnaire for each inspected crop. Information was requested on previous cropping history, winter crops, cultivation methods, residue management, crop type and cultivar, sowing date, irrigation, fungicide, herbicide and fertiliser applications, harvest date and yield.

Relationships between Fusarium levels and species, and crop information were extracted by examining trends between disease/crop pairs of data. The range and mean for each parameter are presented.

\section{RESULTS}

Levels of Fusarium infection in the grain samples ranged from $3 \%$ to $52 \%$ of grains infected, with a mean of $14 \%$. Incidence of Fusarium was greater in spring wheat than in autumn wheat or spring barley. Most spring wheat crops had at least $10 \%$ of grains infected. Only half of the autumn wheat or spring barley crops had similar levels of infection (Table 1). Ear samples from 19 Canterbury wheat crops and eight barley crops were examined for FHB and glume infection with Fusarium. FHB was detected in four (21\%) of the wheat crops. Three of the four were durum wheat crops with between 5\% and $12 \%$ ears infected. Thirty-two percent of wheat crops had visible growth of Microdochium (syn. Fusarium) nivale on the outer surface of glumes, without FHB symptoms. Twenty-five percent of barley crops had traces of FHB.

TABLE 1: Mean incidence of $F$ usarium in grain harvested from wheat and barley crops in 2000.

\begin{tabular}{lcccc}
\hline & $\begin{array}{c}\text { No of } \\
\text { crops }\end{array}$ & $\begin{array}{c}\text { \% grains } \\
\text { infected } \\
\text { (min. - max.) }\end{array}$ & $\begin{array}{c}\% \text { crops with }>10 \% \\
\text { grains infected }\end{array}$ & $\begin{array}{c}\% \text { crops with }>20 \% \\
\text { grains infected }\end{array}$ \\
\hline Autumn wheat & 13 & $11(3-21)$ & 54 & 8 \\
Spring wheat & 11 & $22(6-52)$ & 91 & 45 \\
Spring barley & 16 & $11(3-21)$ & 44 & 6 \\
\hline
\end{tabular}

There were no strong regional differences in the incidence of Fusarium. The North Island and South Canterbury had the highest proportion of crops with at least $20 \%$ of grains infected (Table 2), which contributed to slightly higher mean infection levels than other regions.

TABLE 2: Mean Fusarium incidence in grain from wheat and barley crops harvested in different regions in $\mathbf{2 0 0 0 .}$

\begin{tabular}{lcccc}
\hline Region & $\begin{array}{c}\text { No of } \\
\text { crops }\end{array}$ & $\begin{array}{c}\% \text { grains } \\
\text { infected } \\
\text { (min. - max.) }\end{array}$ & $\begin{array}{c}\% \text { crops with }>10 \% \\
\text { grains infected }\end{array}$ & $\begin{array}{c}\% \text { crops with }>20 \% \\
\text { grains infected }\end{array}$ \\
\hline North Island & 9 & $15(3-52)$ & 44 & 22 \\
North Canterbury & 7 & $11(5-21)$ & 42 & 14 \\
Mid Canterbury & 13 & $13(3-29)$ & 69 & 8 \\
South Canterbury & 8 & $17(7-37)$ & 63 & 0 \\
Southland & 3 & $12(10-15)$ & 100 & 38 \\
\hline
\end{tabular}


Previous crop had no general effects incidence of Fusarium (Table 3). However, the highest incidence of grain infection (52\%) was found in a crop of cv. Otane (highly susceptible to FHB) sown into a paddock after maize.

TABLE 3: Mean incidence of Fusarium in grain from wheat and barley crops categorised by cropping history.

\begin{tabular}{lcccc}
\hline & $\begin{array}{c}\text { No of } \\
\text { crops }\end{array}$ & $\begin{array}{c}\% \text { grains } \\
\text { infected } \\
\text { (min. - max.) }\end{array}$ & $\begin{array}{c}\% \text { crops with }>10 \% \\
\text { grains infected }\end{array}$ & $\begin{array}{c}\% \text { crops with }>20 \% \\
\text { grains infected }\end{array}$ \\
\hline Previous crop & & & & \\
\hline Gramineae & 22 & $14(3-52)$ & 53 & 11 \\
Non-gramineae & 17 & $14(3-29)$ & 65 & 18 \\
No. grass/cereal crops (previous 3 years) & & 57 & 14 \\
\hline 1 & 7 & $13(3-21)$ & 69 & 13 \\
2 & 17 & $13(4-29)$ & 46 & 15 \\
3 & 15 & $16(6-52)$ & & \\
\hline
\end{tabular}

Incidence of grain infection with Fusarium was, on average, lower where the previous crop was burned than when it had been baled, incorporated or left on the surface (Table 4).

TABLE 4: Mean incidence of Fusarium in grain from wheat and barley crops categorised by management of previous crop residues.

\begin{tabular}{lcc}
\hline Previous crop: & No. of crops & \% grains infected (min. - max.) \\
\hline Baled & 15 & $18(5-52)$ \\
Burned & 9 & $10(6-15)$ \\
Incorporated & 7 & $17(3-27)$ \\
Left on surface & 2 & $16(15-17)$ \\
\hline
\end{tabular}

Crops received between nil and four fungicide applications. Fungicide mixtures were common, and most fungicides were applied at less than the manufacturer's recommended rate. There was no clear effect of number of fungicide applications on Fusarium incidence.

Thirteen wheat cultivars (Apollo, Belfield, Centaur, Commando, Consort, CRAW013, CRDW17, Domino, Hussar, Karamu, Kotuku, Monad and Otane) and four barley cultivars (Dash, Optic, Sherwood and Valetta) were represented in the survey. Two cultivars, Otane (bread wheat) and CRDW17 (durum wheat), had a mean incidence of grain infection over 20\% (28 and 27\% respectively). Five cultivars (CRAW013, Hussar, Dash, Sherwood and Valetta) averaged less than $10 \%$ infected grains.

There were regional differences in the complex of Fusarium species found on harvested grain (Table 5). Fusarium graminearum and M. nivale predominated in North Island grain samples. Fusarium avenaceum was most common in South Canterbury samples, although it was isolated in samples from all regions. Fusarium culmorum was most often isolated from Canterbury samples. Microdochium nivale was the most common species found in Southland samples. 
TABLE 5: Mean incidence of different Fusarium species on wheat and barley grain harvested from different regions in 2000.

\begin{tabular}{|c|c|c|c|c|c|c|}
\hline & \multicolumn{6}{|c|}{ Percent grains infected } \\
\hline & North & North & Mid & South & South- & All \\
\hline & Island & Canterbus & anterbur & Canterbur & ry land & regions \\
\hline F. graminearum Schwabe & 4.6 & 0.9 & 0.4 & 1.0 & 0.3 & 1.9 \\
\hline F. avenaceum (Fr.) Sacc & 1.3 & 2.2 & 6.3 & 10.6 & 2.3 & 4.6 \\
\hline F. culmorum (W.G. Smith) Sacc. & 0.3 & 1.9 & 0.1 & 1.2 & 0.0 & 0.9 \\
\hline F. poae (Peck) Wollenw. & 1.0 & 0.0 & 0.0 & 0.1 & 0.0 & 0.3 \\
\hline F. crookwellense Burgess et al. & 0.5 & 0.5 & 0.1 & 0.4 & 0.1 & 0.4 \\
\hline F. sambucinum Fuckel & 0.0 & 0.1 & 0.1 & 0.3 & 0.0 & 0.1 \\
\hline F. heterosporium Nees ex Fr. & 0.1 & 0.0 & 0.0 & 0.0 & 0.0 & 0.3 \\
\hline M. nivale (Fries) Samuels \& Hallet & 6.1 & 4.1 & 4.7 & 2.5 & 6.8 & 4.6 \\
\hline
\end{tabular}

\section{DISCUSSION}

Crop type and region were the two main factors associated with Fusarium incidence in wheat and barley grain harvested in 2000. Samples from spring wheat crops had, on average, twice the percentage of grains infected with Fusarium compared with samples from autumn wheat or spring barley. Several factors may be responsible. Two wheat cultivars, Otane and CRDW17, had particularly high levels of infection. Both have been found to be highly susceptible to FHB in other studies (M. Cromey, unpubl. data). All three CRDW17 crops surveyed in Canterbury had visible FHB, compared with 1 of 16 other wheat crops. Otane was commonly grown in the North Island, and two of the three CRDW 17 crops were grown in South Canterbury, which contributed to the slightly higher mean infection levels in these regions compared with others. In an earlier study, Sayer \& Lauren (1991) also found consistently higher infection levels in North Island crops than in those from the South Island. Rainfall during flowering is a major contributing factor to FHB development (Parry et al. 1995) and may explain some of the regional differences in our study.

Previous cropping history was not associated with the mean infection levels, but a separate study is being carried out to examine the influence of previous maize crops in the North Island on subsequent wheat crops. Results so far, including the one example here, suggest that infection is generally higher following maize than following other crops (M. Cromey, unpubl. data).

The way previous crop residues were managed appeared to influence levels of Fusarium in subsequent cereal crops. Lowest levels were recorded where residues were burned, and this practice is likely to most effectively remove Fusarium inoculum.

The number of fungicide applications was not associated with infection levels. Other research (Suty et al. 1996; M. Cromey, unpubl. data) has shown that product and time of application are important, and that application of an effective fungicide during flowering is critical for controlling FHB and reducing Fusarium levels.

There were big differences in Fusarium species composition between regions. The species range and regional differences are in line with previous New Zealand (Sayer \& Lauren 1991) and overseas (Parry et al. 1995) studies. FHB has been linked to at least 17 causal organisms, but most records are associated with five species: F. culmorum, $F$. avenaceum, $F$. graminearum, $F$. poae and $M$. nivale, with the first three species predominating (Parry et al. 1995). Almost all of our isolations were of these five species.

Parry et al. (1995) also suggest that the geographical distribution of species is related to temperature requirements. Fusarium. graminearum is the most important species in hotter regions, with $F$. culmorum predominating in the cooler maritime regions where $F$. poae and $M$. nivale also assume a greater importance. Fusarium avenaceum is isolated over a range of climatic zones. Similarly, in our study we isolated $F$. graminearum 
primarily from the northern-most region, F. culmorum mostly from Canterbury, and F. avenaceum from all regions.

Inoculation experiments (Jennings \& Turner 1996) have confirmed the importance of rainfall during flowering on FHB occurrence, and therefore grain Fusarium infection. Jennings \& Turner (1996) also found that different Fusarium species had different humidity requirements for ear infection. They found that increasing humidity resulted in earlier development and increased incidence of $F$. culmorum, $F$. graminearum and F. avenaceum. Fusarium poae was less affected by humidity, but M. nivale did not infect below a certain humidity threshold. In our study, $M$. nivale incidence was greatest in samples from the North Island and Southland, where there tends to be higher humidity than in Canterbury.

The incidence and species range of Fusarium in grain harvested from New Zealand wheat and barley crops in 2000 appeared to be influenced by several factors. Crop type and cultivar, along with region, were the major factors. Differences are also likely to occur between years because humidity, especially during flowering and grain fill, is also important for infection and development of FHB.

\section{ACKNOWLEDGEMENTS}

Funding for this research was provided by the New Zealand Foundation for Research, Science and Technology and the Foundation for Arable Research. We also thank the growers of individual crops for providing the crops to inspect and for crop management information.

\section{REFERENCES}

Bai, G.; Shaner, G. 1994: Scab of wheat: prospects for control. Plant Disease 78: 760766.

Burgess, L.W.; Summerell, B.A.; Bullock, S.; Gott, K.P.; Backhouse, D. 1994: Laboratory manual for Fusarium research. Third edition. Sydney, University of Sydney. 133 p.

Jennings, P.; Turner, J.A. 1996: Towards the prediction of fusarium ear blight epidemics in the UK - the role of humidity in disease development. Brighton Crop Prot. Conf. - Pests \& Diseases: 233-238.

Parry, D.W.; Jenkinson, P.; McLeod, L. 1995: Fusarium ear blight (scab) in small grain cereals - a review. Plant Path. 44: 207-238.

Sayer, S.T.; Lauren, D.R. 1991: Fusarium infection in New Zealand grain. N.Z. J. Crop Hort. Sci. 19: 143-148.

Suty, A; Mauler-Machnik, A.; Couron, R. 1996: New findings on the epidemiology of fusarium ear blight on wheat and its control with tebuconazole. Brighton Crop Prot. Conf. - Pests and Diseases: 511-516. 